\title{
Long non-coding RNA, CHRF, predicts poor prognosis of lung adenocarcinoma and promotes cell proliferation and migration
}

\author{
XIAOWEI XIE $^{1 *}$, WEI ZHAO ${ }^{2 *}$, JINGLIN PANG $^{1}$, XIAOMIAO XIONG $^{1}$, HAIYAN WANG $^{1}$ and LINGYUN MA ${ }^{1^{*}}$ \\ ${ }^{1}$ Respiratory Department, The First Affiliated Hospital of Chinese People's Liberation Army General Hospital, \\ Beijing 100048; ${ }^{2}$ Respiratory Department, Chinese People's Liberation Army General Hospital, Beijing 100853, P.R. China
}

Received September 6, 2017; Accepted February 27, 2018

DOI: 10.3892/ol.2018.9425

\begin{abstract}
Research has demonstrated that long non-coding RNAs (lncRNAs) are crucial factors in carcinogenesis. LncRNA, cardiac hypertrophy-related factor (CHRF), has been demonstrated to act as an oncogene in a variety of types of tumor. However, its biological function in lung adenocarcinoma remains to be elucidated. The present study aimed to examine the level of CHRF expression in lung adenocarcinoma tissues and cell lines, and to analyze the association between CHRF and clinicopathological characteristics, as well prognosis of patients with lung adenocarcinoma. Loss-of-function assays were performed to determine the biological function of CHRF. The expression of CHRF was markedly upregulated in lung adenocarcinoma tissues and cell lines. Patients exhibiting upregulated CHRF also demonstrated advanced Tumor-Node-Metastasis stage, lymph node metastasis and larger tumor size compared with those exhibiting downregulated CHRF. Results of Cox proportional hazards regression analysis suggested that highly-expressed CHRF may be regarded as an independent prognostic factor of prognosis. In addition, loss-of-function assays indicated that downregulation of CHRF suppressed cell proliferation, migration and invasion, and induced cell cycle arrest and apoptosis. Western blotting revealed that the phosphoinositide-3-kinase/Akt signaling pathway activity is reduced in lung adenocarcinoma following the knockdown of CHRF. Together, these results indicate that lncRNA, CHRF, may serve a critical role in the development and progression of lung adenocarcinoma, and may act as a novel prognostic biomarker and therapeutic target in lung adenocarcinoma.
\end{abstract}

Correspondence to: Dr Lingyun Ma, Respiratory Department, The First Affiliated Hospital of Chinese People's Liberation Army General Hospital, 51 Fuchen Road, Beijing 100048, P.R. China E-mail: lingyunma1@163.com

*Contributed equally

Key words: long non-coding RNA, cardiac hypertrophy-related factor, lung adenocarcinoma, proliferation, migration

\section{Introduction}

Lung cancer is one of the leading causes of cancer-associated mortality, with a 5-year-survival rate of $17 \%$ worldwide (1). Non-small cell lung cancer (NSCLC) accounts for $85 \%$ all lung cancer cases in China, in 2017 (2). NSCLC can be subcategorized into adenocarcinoma (LAD), squamous cell carcinoma (SCC) or large cell carcinoma. Despite improvements in chemotherapy, radiation and surgical treatments, lung cancer remains accountable for a large proportion of cancer-associated mortality (3). The average 5-year survival rate of lung cancer is approximately $<15 \%$ in the urban areas of China (4-7). The increase in incidence of LAD has caused socioeconomic developmental and environmental concerns (8), and the underlying mechanisms of LAD remain unclear.

Long non-coding RNAs (lncRNAs) are a class of RNA transcripts $>200$ nucleotides in length, with no clear protein-coding ability (9). Thus far, $>300$ lncRNAs have been annotated in the IncRNA database, the majority of which have been studied in humans (10). Previous studies have demonstrated that lncRNAs serve important roles in various biological processes in numerous diseases, including various forms of cancer $(9,11-13)$. LncRNAs function in the regulation of complicated mechanisms and participate in physiological, pathological and cytobiological functions, including apoptosis, cell proliferation and chemoresistance (14-16). LncRNA cardiac hypertrophy-related factor (CHRF) has recently been reported to act as an oncogene; Qiuyun Wu et al (17) demonstrated that lncRNA CHRF functions as an endogenous 'sponge' of micro RNA (miR)-489, repressing miR-489 activity and functioning in pulmonary fibrosis.

In the present study, it was revealed that the expression of CHRF in LAD tissues and cell lines was increased compared with the negative controls. Loss-of-function assays were performed to analyze the effects of CHRF on the proliferation, cell cycle, apoptosis, migration and invasion of LAD cells. Western blotting was performed to study the relevance of CHRF in the phosphoinositide-3-kinase (PI3K)/Akt signaling pathway. These experiments indicated that CHRF may be considered as a novel prognostic factor and a therapeutic target for LAD.

\section{Materials and methods}

Tissues samples. A total of 80 LAD tissues and matched adjacent normal tissues were collected from patients 
treated at the First Affiliated Hospital of Chinese PLA General Hospital (Beijing, China) between August 2010 and August 2013. The age of these patients range from 45 to 75 years (mean age: 55 years). The sex ratio of these patients is 38 males and 42 females). Inclusion criteria: Patients with lung adenocarcinoma who have never received radiotherapy or chemotherapy. Exclusion criteria: Patients who were diagnosed as pneumonia in addition to LAD or those whose course of disease was not visited and recorded. The present study was a retrospective study. The LAD diagnosis of all tissues had been histopathologically confirmed, and frozen in liquid nitrogen. All patients provided written informed consent for use of tissue in the present research. The study protocol was approved by the Ethics Committee of the First Affiliated Hospital of Chinese PLA General Hospital (Beijing, China).

Cell culture and transfection. The human LAD cell lines, SPC-A1, NCI-H441 and NCI-H1975, and the normal lung epithelial cell, BEAS-2B, were purchased from The Cell Bank of Type Culture Collection of the Chinese Academy of Sciences (Shanghai, China). BEAS-2B cells were incubated in complete medium [RPMI-1640+10\% fetal bovine serum (FBS; Lonza Group, Ltd., Basel, Switzerland)]. LAD cells were cultured and incubated in medium (DMEM+10\% FBS). All mediums were purchased from Thermo Fisher Scientific, Inc. (Waltham, MA, USA). All cell lines were incubated in a humidified atmosphere at $37^{\circ} \mathrm{C}$ with $5 \% \mathrm{CO}_{2}$. The complete medium was replaced every 2-3 days.

The LAD cell lines (500 cells/well) were transfected with $50 \mathrm{nM}$ small interfering RNA (si)-CHRF or si-negative control (NC) using Lipofectamine ${ }^{\circledR} 2000$ (Thermo Fisher Scientific, Inc.), according to the manufacturer's instructions. The si-CHRF expression vector and matched scrambled control vectors were synthesized and purchased from GeneCopoeia, Inc. (Rockville, MD, USA). To obtain the optimal transfection efficiency, we used two siRNAs to knock down CHRF. They are si-CHRF\#1 and si-CHRF\#2. The siRNA sequences used are as follows: si-CHRF\#1: 5'-TGCCTCTCTAGAGAGCAG C-3'; si-CHRF\#2: (5'-CCGATCTGACATGACTGCG-3'. A total of $48 \mathrm{~h}$ after transfection, the cells were harvested for RNA extraction and reverse transcription-quantitative polymerase chain reaction (RT-qPCR) analysis. All experiments were performed in triplicate.

$R N A$ extraction and RT- $q P C R$. Total RNA was extracted from LAD tissues or cells using TRIzol (Thermo Fisher Scientific, Inc.), according to manufacturer's instructions. RNA samples were stored at $-80^{\circ} \mathrm{C}$. A One-Step SYBR RT-PCR kit (Takara Bio, Inc., Otsu, Japan) was used to determine the expression of CHRF using a 7500 Real-Time PCR System (Applied Biosystems; Thermo Fisher Scientific, Inc.). Each reaction contained $2 \mu \mathrm{l}$ total RNA template, $1 \mu \mathrm{l}$ forward primer, $1 \mu \mathrm{l}$ reverse primer and $16 \mu \mathrm{l}$ reaction mixture. The thermocycling conditions were as follows: Stage 1 (reverse transcription reaction), 1 cycle of $42^{\circ} \mathrm{C}$ for $5 \mathrm{~min}, 95^{\circ} \mathrm{C}$ for $10 \mathrm{sec}$; Stage 2 (PCR reaction), 40 cycles of $95^{\circ} \mathrm{C}$ for $5 \mathrm{sec}, 60^{\circ} \mathrm{C}$ for $34 \mathrm{sec}$; Stage 3 (dissociation curve analysis), $95^{\circ} \mathrm{C}$ for $15 \mathrm{sec}, 40$ cycles of $65^{\circ} \mathrm{C}$ for $1 \mathrm{~min}$ and $95^{\circ} \mathrm{C}$ for $14 \mathrm{sec}$. The primers used for $\mathrm{CHRF}$ and GAPDH were purchased from Sangon Biotech Co., Ltd.
(Shanghai, China). The primers are as follows: Human CHRF forward primer: 5'-AGATTCACATGGTATCCTGAAC'; reverse: 5'-TAGTCTGGCCACATTTTGTCTC-3'. GAPDH forward primer: 5'-TGTGTCCGTCGTGGATCTGA-3'; reverse: 5'-CCTGCTTCACCACCTTCTTGA-3'. All experiments were performed in triplicate. The qPCR quantification was conducted according to the $2^{-\Delta \Delta \mathrm{Cq}}$ method (18).

Cell proliferation assay. A total of either SPCA-1 or NCI-H441 $2 \times 10^{4}$ cells/well were seeded in 96-well plates. A total of $20 \mu 1$ MTT solution $(0.5 \mathrm{mg} / \mathrm{ml}$; Sigma-Aldrich; Merck KGaA, Darmstadt, Germany) was added to each well, followed by incubation at $37^{\circ} \mathrm{C}$ for $4 \mathrm{~h}$. The cell culture medium was then carefully aspirated, and the formazan crystals were dissolved in $0.2 \mathrm{ml}$ dimethyl sulfoxide. Absorbance was measured at $490 \mathrm{~nm}$ on a SpectraMax M5 microplate reader. All experiments were performed in triplicate.

Flow cytometry. Quantification of apoptosis was performed using an AnnexinV-FITC Apoptosis Detection kit (Beijing Biosea Biotechnology Co., Ltd., Beijing, China) 48 h after transfection, according to the manufacturers' protocol. The results were analyzed using CellQuest software v.0.9.13 (BD, Franklin Lakes, NJ, USA). Cells in the right lower quadrant were considered to be apoptotic. For cell cycle analysis, $1 \times 10^{6}$ cells were fixed. To fix cell, $0.5 \mathrm{ml}$ of cold PBS was used to resuspend cells. Next, the resuspended cells were added into $1.2 \mathrm{ml}$ of $99.7 \%$ absolute ethyl alcohol (The final concentration is $70 \%$ ). Finally, the resuspended cells were fixed at $4^{\circ} \mathrm{C}$ overnight. The cells were then stained with propidium iodide $(50 \mu \mathrm{g} / \mathrm{ml})$ at $4^{\circ} \mathrm{C}$ for $30 \mathrm{~min}$ in the dark. The cell cycle distribution was analyzed by using FlowJo 7.6.1 (FlowJo, LLC, Ashland, Oregon, USA). All experiments were performed in triplicate.

Transwell assay. Cell invasion ability of SPCA-1 and NCI-H441 cells was assessed using Costar transwell chambers (Corning Incorporated, Corning, NY, USA) containing polycarbonate membranes $(6.5 \mathrm{~mm}$ in diameter with a pore size of $8 \mu \mathrm{m}$ ), according to the manufacturer's protocol. The transwell membranes were each coated with $80 \mu$ l Matrigel (500 ng/ $\mu \mathrm{l}$; BD Biosciences, Franklin Lakes, NJ, USA), and incubated at $37^{\circ} \mathrm{C}$ for $4 \mathrm{~h}$. A total of $2 \times 10^{5}$ cells were added to the upper compartment of each well in $200 \mu 1$ of PFHM-II Protein-Free Hybridoma Medium (Gibco: Thermo Fisher Scientific, Inc.); supernatant complete medium of cells $(0.5 \mathrm{ml})$ was added to the bottom chamber. Following incubation for $24 \mathrm{~h}$ at $37^{\circ} \mathrm{C}$, the cells which had invaded to the lower chamber were stained with hematoxylin and eosin (Thermo Fisher Scientific, Inc.). Cells were fixed with $95 \%$ ethanol for $10 \mathrm{~min}$ at $37^{\circ} \mathrm{C}$ and then stained with $19 \%$ hematoxylin for $20 \mathrm{~min}$ and $0.5 \%$ eosin for $3 \mathrm{~min}$ at $37^{\circ} \mathrm{C}$., Then it was counted under a light microscope at a magnification of $\mathrm{x} 1,000$ and the number was counted within randomly nine field for each experiment. All experiments were performed in triplicate.

Western blot analysis. Cell proteins were isolated using $400 \mu 1$ of RIPA buffer (Thermo Fisher Scientific, Inc.). Gels were scanned and quantified by densitometry using 
A

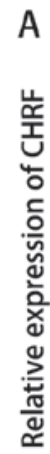

A

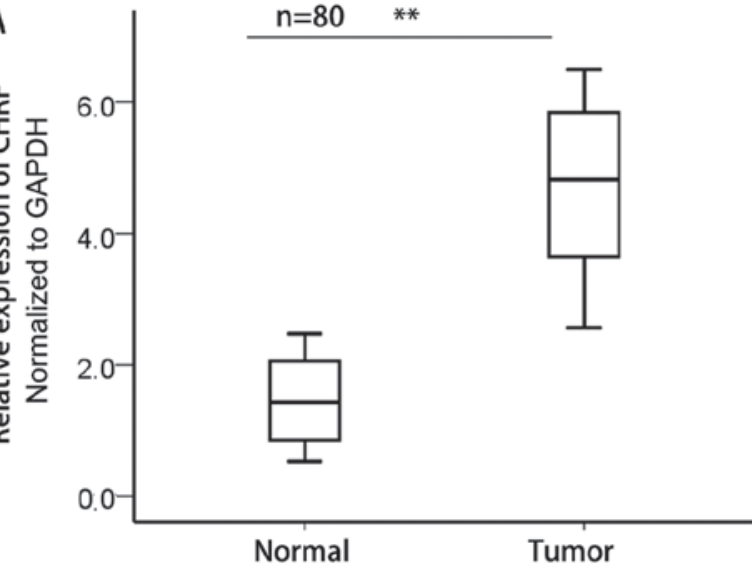

B

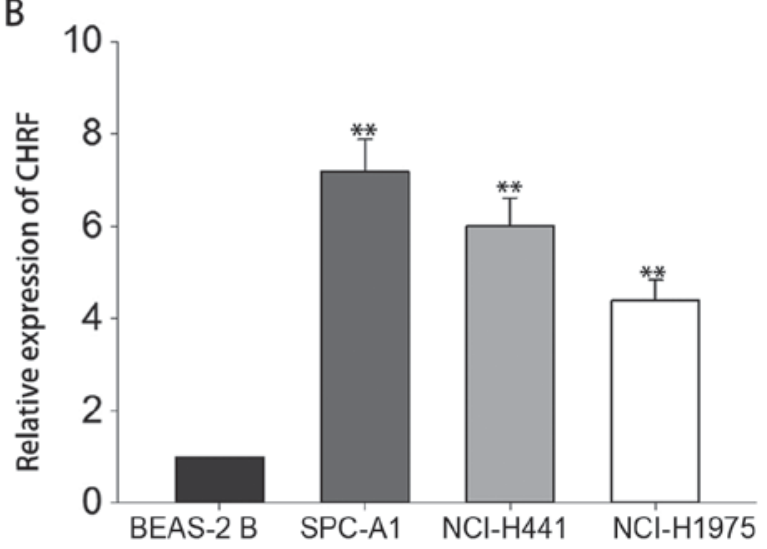

Figure 1. LncRNA CHRF expression is upregulated in lung adenocarcinoma tissues and cell lines. (A) The expression level of CHRF in LAD tissues and matched adjacent normal tissues. (B) The expression level of CHRF in LAD cell lines, SPC-A1, NCI-H441, NCI-H1975, and in normal BEAS-2B cells. Error bars represented the mean \pm standard deviation of $\geq 3$ independent experiments. ${ }^{* *} \mathrm{P}<0.01$ vs. BEAS- 2 B group. LncRNA, long non-coding RNA; CHRF, cardiac hypertrophy-related factor; LAD, lung adenocarcinoma.

the Quantity-One 4.4 software (Bio-Rad, Laboratories, Inc., CA, USA). The protein was quantified by using the Bradford method (Bio-Rad, Laboratories, Inc.). The sample solution containing $50 \mu \mathrm{g}$ proteins were separated by $10 \%$ SDS-PAGE, then transferred into nitrocellulose membranes (Merck KGaA, Darmstadt, Germany). The membranes were blocked with $5 \%$ non-fat dry milk in Tris-buffered saline with $1 \%$ Tween (TBS) for $1 \mathrm{~h}$, then incubated with the following primary antibodies overnight at $4^{\circ} \mathrm{C}$ : Phosphorylated (p-)PI3K (cat no. ab125633, 1:2,000), total PI3K (cat no. ab127617, 1:2,000), p-AKT (cat no. ab38449, $1: 2,000)$, total Akt (cat no. ab126580; 1:2,000) and GAPDH (cat no. ab8245; 1:2,000) (all from Abcam, Cambridge, UK). The secondary antibody (anti-mouse IgG) conjugated to horseradish peroxidase (cat no. 7076, 1:300; Cell Signaling Technology, Inc., Danvers, MA, USA) was incubated with the membranes for $1 \mathrm{~h}$ at $37^{\circ} \mathrm{C}$. Protein binds were visualized using an enhanced chemiluminescence reagent chromogenic substrate (Pierce; Thermo Fisher Scientific, Inc.), according to the manufacturer's protocol. All experiments were performed in triplicate.

Statistical analysis. All statistical analysis was performed using SPSS software (version 19.0; IBM Corp., Armonk, NY, USA). The data were analyzed and presented as the mean \pm standard deviation. Data between two groups were analyzed by using the paired-student t-test. Multiple comparisons were made by one-way ANOVA with the Least Significant Difference post hoc test. Correlations between CHRF expression and clinicopathological features of LAD patients were analyzed by Pearson $\chi^{2}$ test. Survival analysis was performed using the Kaplan-Meier method and the log-rank test was used to compare differences between patient groups. $\mathrm{P}<0.05$ was considered to indicate a statistically significant difference.

\section{Results}

CHRF expression is upregulated in lung adenocarcinoma tissues and cell lines. To determine the role of the lncRNA,
$\mathrm{CHRF}$, in the development and progression of lung adenocarcinoma (LAD), RT-qPCR was performed to measure the expression of CHRF in 80 pairs of LAD tissues and adjacent normal tissues. The results revealed that $\mathrm{CHRF}$ was significantly increased in LAD tissues compared with adjacent normal tissues (Fig. 1A, $\mathrm{P}<0.01$ ). The expression level of CHRF was also measured in LAD cell lines and the normal lung epithelial BEAS-2B cells. As demonstrated in Fig. 1B, the level of CHRF was increased in LAD cells compared with normal epithelial cells $(\mathrm{P}<0.01)$. The level of CHRF was highest in SPC-A1 and NCI-H441 cells, which were selected for use in subsequent experiments. These results suggest that $\mathrm{CHRF}$ may serve a crucial role in the development of LAD.

Association between the expression of CHRF and clinicopathological characteristics of LAD patients. In order to explore the association between CHRF and various clinicopathological characteristics of LAD patients, the mean value of CHRF expression in LAD tissue was used as a cutoff value (patients exhibiting expression higher than the cutoff value were classified into high expression and patients exhibiting expression lower than or equal to the cutoff value were classified into low expression) and all patients were divided into a high expression group $(\mathrm{n}=41)$ and a low expression group $(n=39)$. As presented in Table I, high expression of CHRF was significantly associated with advanced TNM stage, lymph node metastasis and large tumor size $(\mathrm{P}<0.05)$. However, there was no evident association between the expression of CHRF and other characteristics, including age, gender, smoking and differentiation $(\mathrm{P}>0.05)$.

Upregulation of CHRF expression is associated with poor prognosis for patients with LAD. The Kaplan-Meier and the log-rank test were used to investigate the clinical relevance of CHRF in LAD. Patients exhibiting high expression of CHRF had a markedly lower overall survival probability than those with low expression of CHRF (Fig. 2). Univariate and multivariate Cox regression analyses indicated that the expression of CHRF, tumor size and lymph metastasis were associated 
Table I. Association between CHRF expression and clinicopathological characteristics $(n=80)$.

\begin{tabular}{llll}
\hline & \multicolumn{2}{l}{ CHRF expression } & \\
\cline { 2 - 2 } Variable & Low & High & P-value \\
\hline Age & & & \\
$\leq 55$ & 21 & 15 & 0.177 \\
$>55$ & 18 & 26 & \\
Sex & & & \\
$\quad$ Male & 20 & 18 & 0.655 \\
Female & 19 & 23 & \\
Smoking status & & & \\
Smoking & 24 & 17 & 0.080 \\
Non-smoking & 15 & 24 & \\
Differentiation & & & \\
Poor & 17 & 26 & 0.116 \\
$\quad$ Well/moderate & 22 & 15 & \\
Tumor size & & & \\
$\leq 3 \mathrm{~cm}$ & 26 & 13 & $0.003^{\mathrm{b}}$ \\
$>3 \mathrm{~cm}$ & 13 & 28 & \\
TNM stage & & & \\
I-II & 23 & 14 & $0.043^{\mathrm{a}}$ \\
IIIa & 16 & 27 & \\
Lymph metastasis & & & $0.025^{\mathrm{a}}$ \\
Absent & 24 & 14 & \\
Present & 15 & 27 & \\
\hline
\end{tabular}

CHRF, cardiac hypertrophy-related factor; TNM, tumor-node-metastasis. Pearson $\chi^{2}$ test. ${ }^{\mathrm{a}} \mathrm{P}<0.05,{ }^{\mathrm{b}} \mathrm{P}<0.01$.

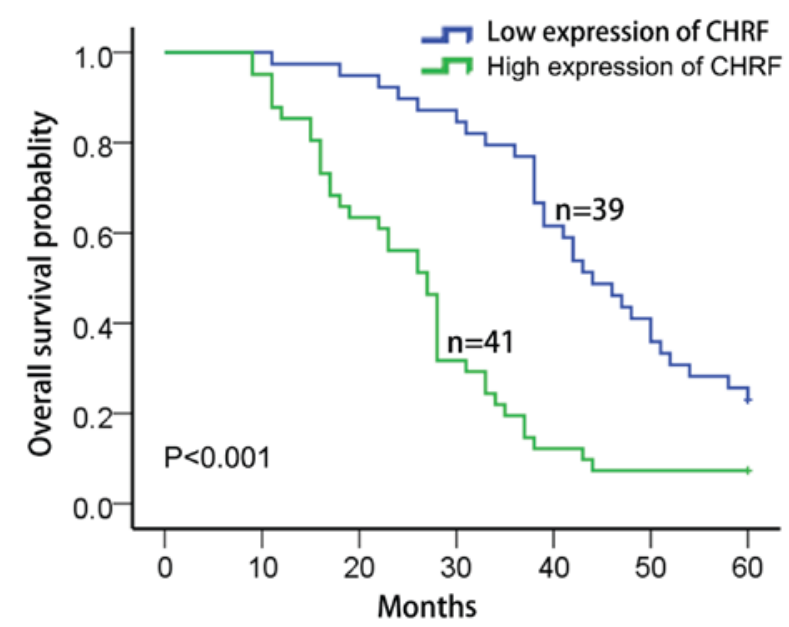

Figure 2. Kaplan-Meier analysis of the association between CHRF expression level and overall survival probability of patients with lung adenocarcinoma $(\mathrm{P}<0.001)$. CHRF, cardiac hypertrophy-related factor.

with the overall survival time of LAD patients. Therefore, lncRNA CHRF may act as an independent prognostic marker for the overall survival time of LAD patients (Table II).
Table II. Multivariate analysis of prognostic parameters in patients with lung adenocarcinoma by Cox regression analysis.

\begin{tabular}{|c|c|c|}
\hline & Multivariate & Univariate \\
\hline Variable & P-value & P-value \\
\hline $\begin{array}{l}\text { Age } \\
\leq 60 \\
>60\end{array}$ & 0.944 & 0.940 \\
\hline $\begin{array}{l}\text { Sex } \\
\text { Male } \\
\text { Female }\end{array}$ & 0.801 & 0.817 \\
\hline $\begin{array}{l}\text { Smoking } \\
\text { Smoking } \\
\text { No smoking }\end{array}$ & 0.510 & 0.341 \\
\hline $\begin{array}{l}\text { Differentiation } \\
\text { Poor } \\
\text { Well/Moderate }\end{array}$ & 0.907 & 0.872 \\
\hline $\begin{array}{l}\text { Tumor size } \\
\leq 3 \mathrm{~cm} \\
>3 \mathrm{~cm}\end{array}$ & $0.001^{\mathrm{b}}$ & $<0.001^{\mathrm{b}}$ \\
\hline $\begin{array}{l}\text { TNM stage } \\
\text { I-II } \\
\text { IIIa }\end{array}$ & 0.105 & 0.111 \\
\hline $\begin{array}{l}\text { Lymph metastasis } \\
\text { Absent } \\
\text { Present }\end{array}$ & $0.048^{\mathrm{a}}$ & $0.032^{\mathrm{a}}$ \\
\hline $\begin{array}{l}\text { CHRF expression } \\
\text { Low } \\
\text { High }\end{array}$ & $0.001^{\mathrm{b}}$ & $<0.001^{\mathrm{b}}$ \\
\hline
\end{tabular}

TNM, tumor-node-metastasis; CHRF, cardiac hypertrophy-related factor ${ }^{\mathrm{a}} \mathrm{P}<0.05,{ }^{\mathrm{b}} \mathrm{P}<0.01$.

Knockdown of CHRF represses cell proliferation by regulating cell cycle and apoptosis. Loss-of-function experiments were performed to investigate the biological function of CHRF in LAD. The results of RT-qPCR analysis revealed that the expression of CHRF was downregulated in si-SPCA-1 and si-NCI-H441 cells compared with the si-NC group $(\mathrm{P}<0.01$; Fig. 3A). MTT assays demonstrated downregulation of CHRF expression significantly reduced cell proliferation both in si-SPCA-1 and si-NCI-H441 cells ( $\mathrm{P}<0.01$; Fig. 3B). Flow cytometry revealed that knockdown of CHRF caused cell cycle arrest most often in the $G_{0} / G_{1}$ phase, and induced cell apoptosis $(\mathrm{P}<0.01$; Fig. $3 \mathrm{C}$ and $\mathrm{D})$. These results indicate that knockdown of CHRF reduced cell proliferation by affecting cell cycle and apoptosis.

Inhibition of CHRF suppresses cell migration and invasion in $L A D$. Transwell assays were performed to further explore the effect of CHRF on the progression of LAD. This demonstrated that cells transfected with si-CHRF were less migratory compared with si-NC cells ( $\mathrm{P}<0.01$; Fig. 4A). Furthermore, 

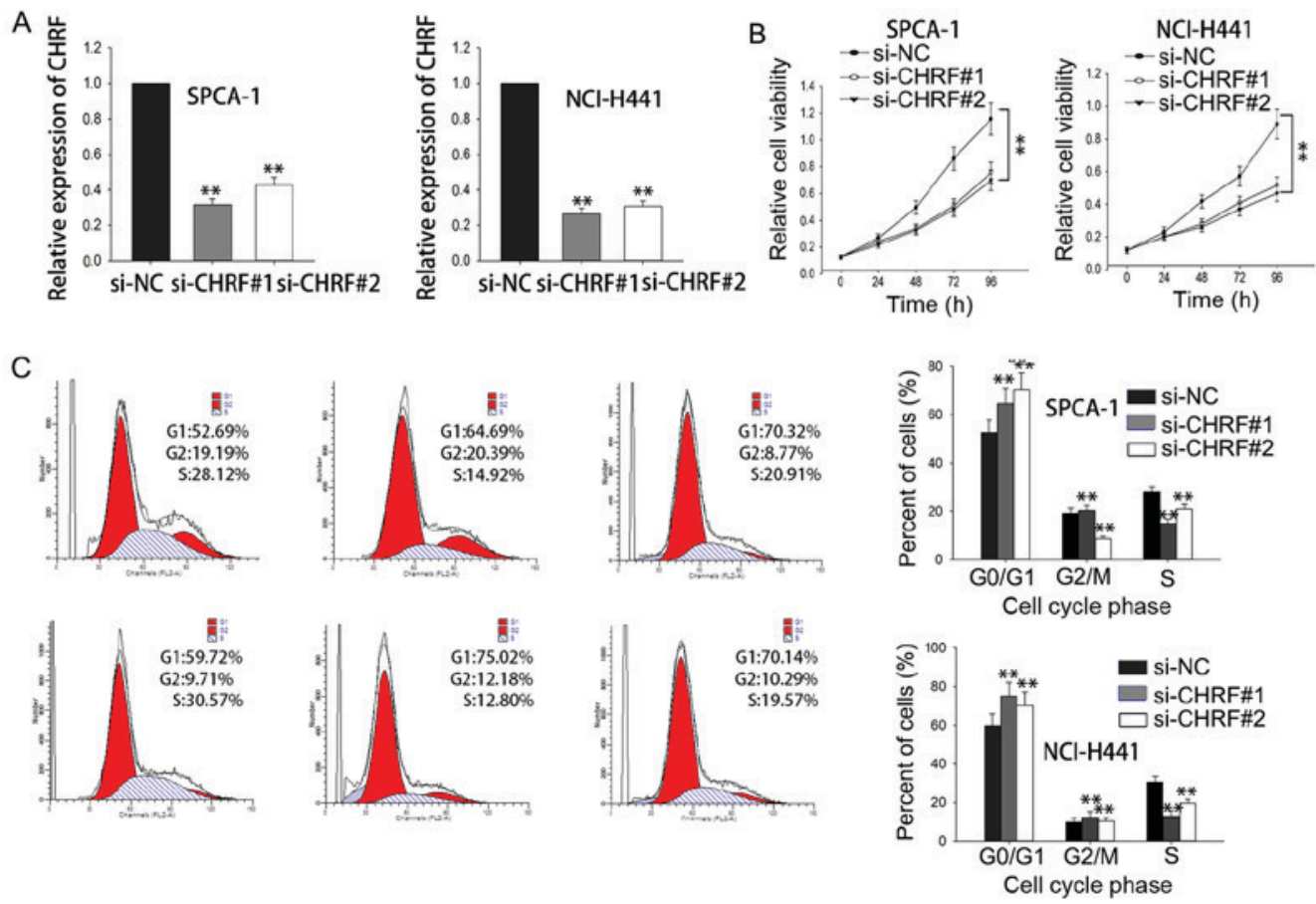

D
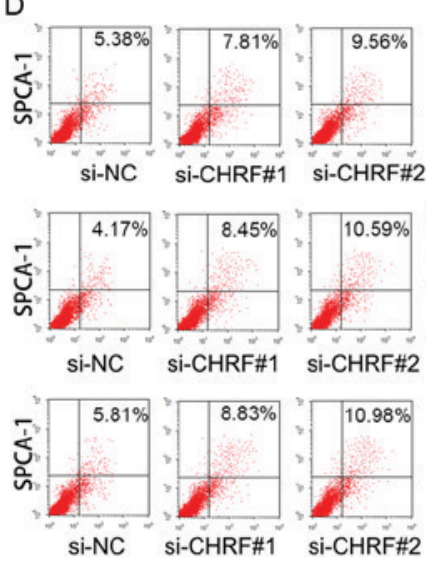
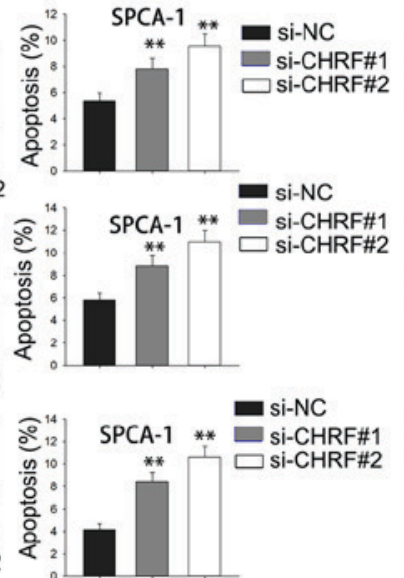
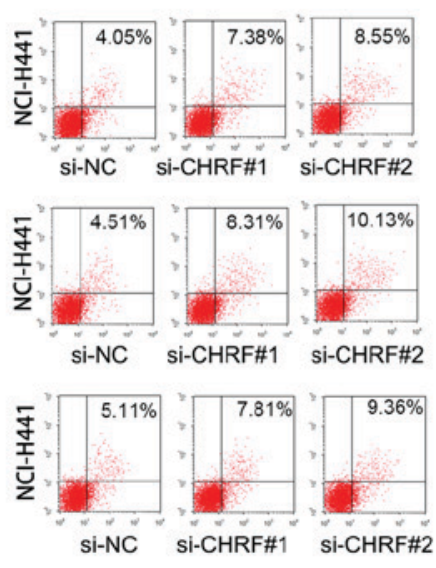
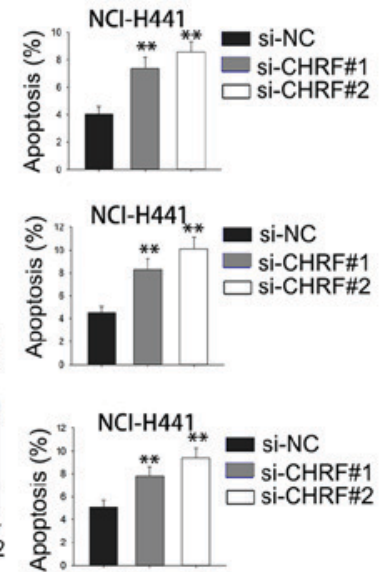

Figure 3. Knockdown of CHRF represses cell proliferation by affecting the cell cycle and apoptosis. (A) Reverse transcription-quantitative polymerase chain reaction was used to measure the expression level of $\mathrm{CHRF}$ in cells transfected with si-CHRF. (B) MTT assays revealed the effect of si-CHRF on cell proliferation of lung adenocarcinoma cells. (C) Flow cytometry was used to analyze the effect of si-CHRF on cell cycle. (D) Flow cytometry was used to analyze the effect of si-CHRF on apoptosis. Error bars represent the mean \pm standard deviation of at $\geq 3$ independent experiments. ${ }^{* *} \mathrm{P}<0.01 \mathrm{vs}$. control group. $\mathrm{CHRF}$, cardiac hypertrophy-related factor; si, small interfering RNA; NC, negative control.

the transwell invasion assay demonstrated that knockdown of CHRF significantly reduced the invasive ability of LAD cells $(\mathrm{P}<0.01$; Fig. 4B). These data suggest that $\mathrm{CHRF}$ functioned as an oncogene in the development and progression of LAD.

Knockdown of CHRF reduces the expression level of protein members of the PI3K/Akt signaling pathway in $L A D$. To explore the potential mechanism through which CHRF affects the progression of LAD, western blotting was performed to determine the effect of downregulated CHRF on the PI3K/Akt signaling, which has been demonstrated to be ectopically activated in human cancers, increasing cell proliferation and metastasis (19). Western blotting revealed that knockdown of CHRF dramatically reduced the protein level of p-PI3K and p-Akt in LAD ( $\mathrm{P}<0.01$; Fig. 5). These data indicate that the PI3K/Akt signaling pathway may function in the proliferation and metastasis of LAD cells induced by CHRF.

\section{Discussion}

Dysregulated expression of lncRNAs has been demonstrated to contribute to the development and progression of various types of human cancer, providing novel therapeutic targets for cancer treatment and drug resistance (20-22). LncRNA $\mathrm{CHRF}$ has been reported to function in numerous human diseases, including a variety of forms of cancer. LncRNA CHRF-induced downregulation of miR-4891 promotes metastasis of colorectal cancer via twist family BHLH transcription factor 1/epithelial-mesenchymal transition signaling pathway (23). Previous studies have reported that miR-489 is regulated by 1 cRNA CHRF $(17,24)$. CHRF also 
A


B
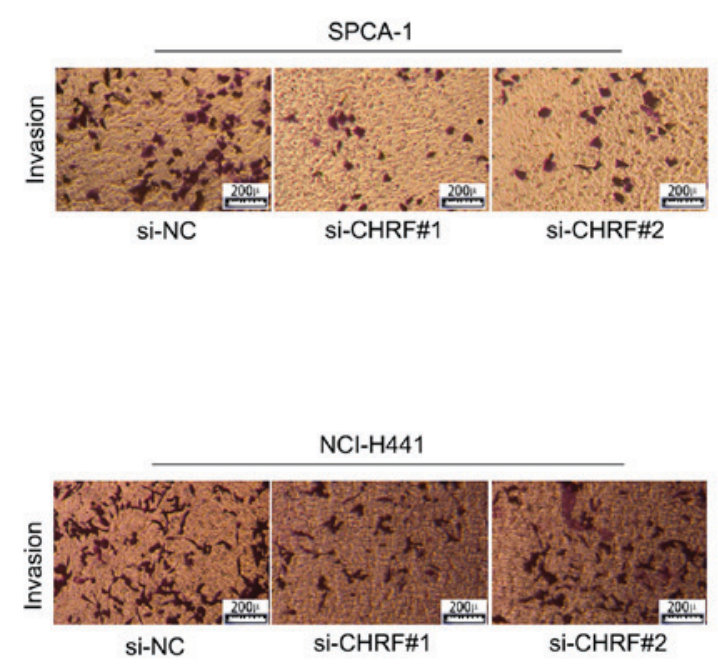
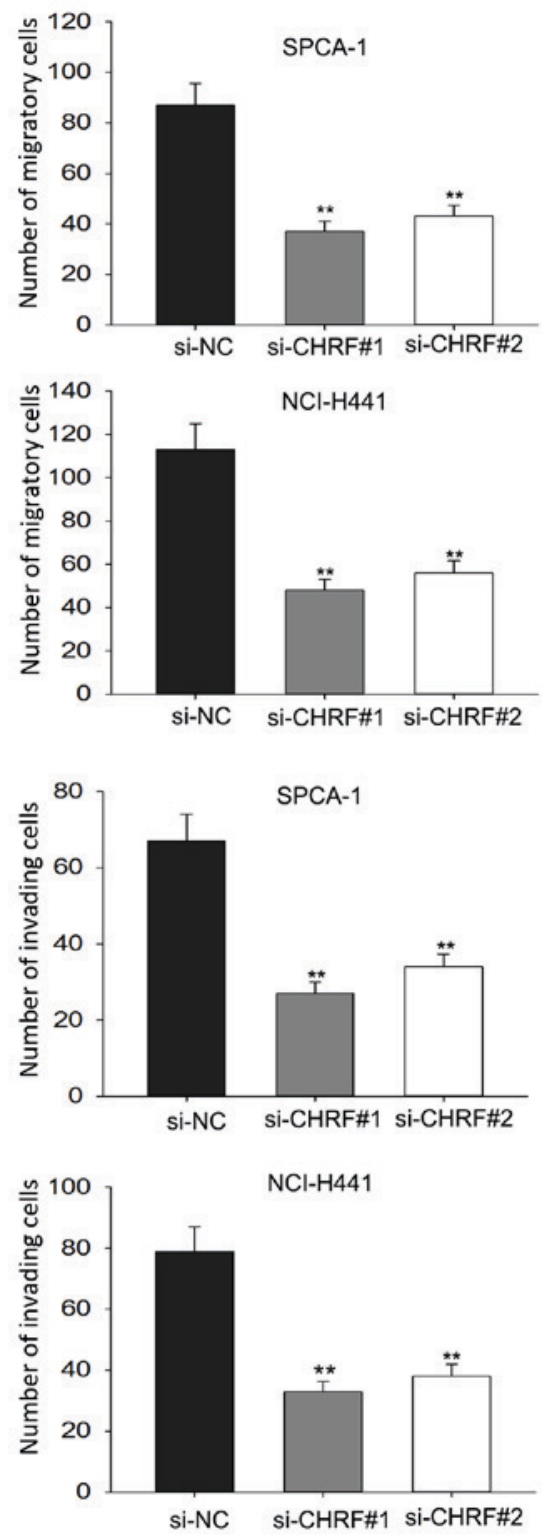

Figure 4. Knockdown of CHRF suppresses cell migration and invasion abilities of LAD cells. (A) Transwell assays demonstrated that knockdown of CHRF inhibited the migratory abilities of LAD cells. (B) Quantification of the transwell assay results showed that the invasive ability of LAD cells was suppressed by $\mathrm{CHRF}$ knockdown. $\mathrm{n}=200 \mu \mathrm{m}$. Error bars represented the mean \pm standard deviation of $\geq 3$ independent experiments. ${ }^{* *} \mathrm{P}<0.01 \mathrm{vs}$. control group. $\mathrm{CHRF}$ cardiac hypertrophy-related factor; LAD, lung adenocarcinoma; SI, small interfering RNA; NC, negative control.

serves critical roles in leukemia (25), human erythroleukemia (26) and myeloid leukemia (27), and is a key regulator the pathology of heart failure (28). However, the molecular mechanisms underlying the process of LAD tumorigenesis remain insufficiently characterized.

The present study demonstrated that CHRF was dramatically overexpressed in LAD tissues and cell lines compared with normal tissues and cells. Overexpression of CHRF was associated with advanced TNM stage, lymph node metastasis and large tumor size. It was also revealed that patients exhibiting high expression of CHRF had a shorter overall survival time compared with those exhibiting low expression of CHRF. Furthermore, loss-of-function assays indicated that knockdown of CHRF inhibited cell proliferation, migration and invasion of LAD.

The PI3K/Akt pathway is a crucial intracellular signaling pathway involved in proliferation and EMT in the various types of cancer (29). It has been demonstrated that lncRNAs serve important roles in PI3K/Akt signaling pathway. For example, it has been reported that downregulation of metastasis associated lung adenocarcinoma transcript 1 induced EMT via the PI3K/Akt pathway in breast cancer (30). Downregulation of lncRNA MALAT1 induces epithelial-to-mesenchymal transition via the PI3K-AKT pathway in breast cancer (31). In the present study, it was demonstrated that knockdown of CHRF decreased the protein expression levels of p-PI3K and p-Akt, suggesting that the PI3K/Akt pathway may function in the CHRF-induced carcinogenesis of LAD.

Overall the present study indicates that CHRF expression is enhanced during the progression of LAD. Overexpression of CHRF was associated with advanced TNM stage, lymph node metastasis and large tumor size in patients with LAD. Downregulation of CHRF expression reduced cell proliferation and metastasis in LAD. Furthermore, knockdown of 
A

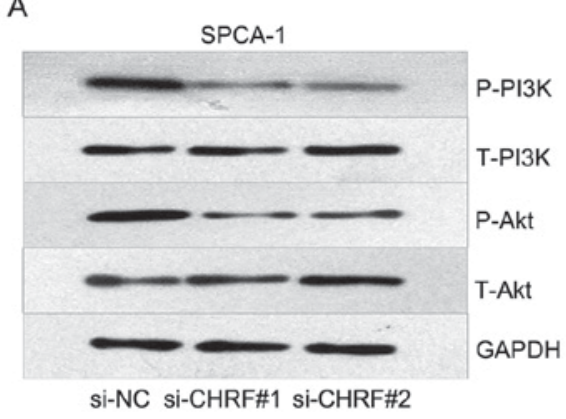

в



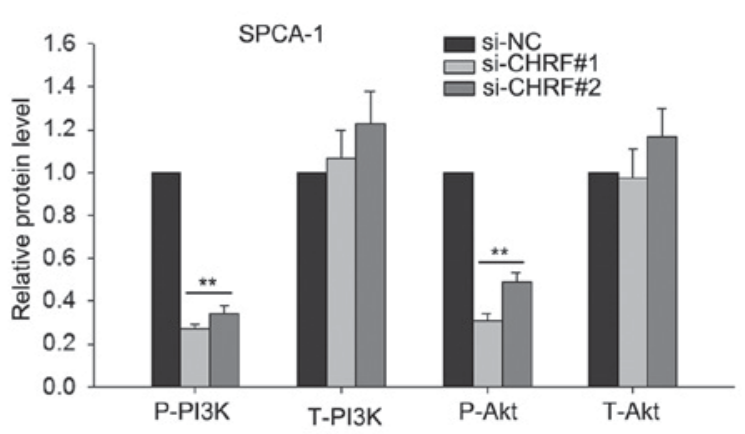

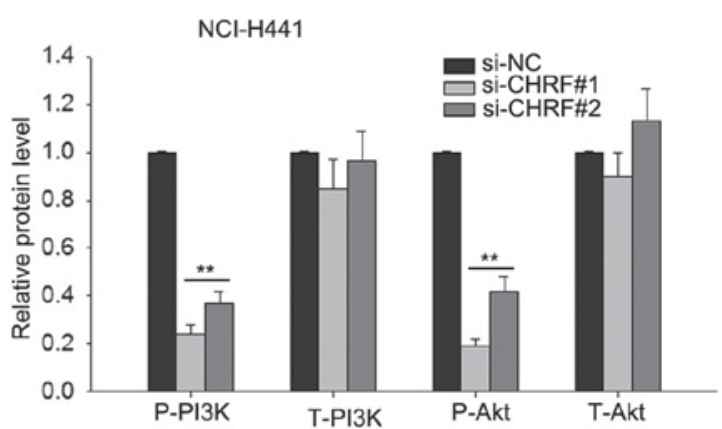

Figure 5. Knockdown of CHRF reduces the protein expression level of PI3K/Akt pathway in LAD. Western blotting revealed that knockdown of CHRF decreased the protein expression levels of p-PI3K and p-Akt in (A) SPCA-1 and (B) NCI-H441 cells. Error bars represented the mean \pm standard deviation of $\geq 3$ independent experiments. ${ }^{* *} \mathrm{P}<0.01$ vs. control group. CHRF, cardiac hypertrophy-related factor; PI3K, posphoinositide-3-kinase; LAD, lung adenocarcinoma; p-, phosphorylated; T-total; si, small interfering RNA; NC, negative control.

CHRF resulted in reduced activity of the PI3K/Akt signaling pathway. Thus, CHRF may be a novel molecular target for the diagnosis and therapy of LAD.

\section{Acknowledgements}

Not applicable.

\section{Funding}

The present study was supported by funding of the Chinese PLA General Hospital (grant no., 2016FC-304M-TSYS-04).

\section{Availability of data and materials}

All data generated or analyzed during this study are included in this published article.

\section{Authors' contributions}

XXie, WZ, JP, XXio, HW and LM were responsible for the completion of experiments. XXie and WZ undertook study design and wrote the manuscript.

\section{Ethics approval and consent to participate}

All patients provided written informed consent for the use of their tissue in the present research. The study protocol was approved by the Ethics Committee of the First Affiliated Hospital of Chinese PLA General Hospital (Beijing, China).

\section{Consent for publication}

All patients, researchers and authors participated in this study have provided written informed consent for the publication of any associated data and accompanying images.

\section{Competing interests}

The authors declare that they have no competing interests.

\section{References}

1. Jemal A, Bray F, Center MM, Ferlay J, Ward E and Forman D: Global cancer statistics. CA Cancer J Clin 61: 69-90, 2011.

2. Chen J, Zhang F, Wang J, Hu L, Chen J, Xu G and Wang Y: LncRNA LINC01512 promotes the progression and enhances oncogenic ability of lung adenocarcinoma. J Cell Biochem 118: 3102-3110, 2017.

3. Gridelli C, Rossi A and Maione P: Treatment of non-small-cell lung cancer: State of the art and development of new biologic agents. Oncogene 22: 6629-6638, 2003.

4. Chen CH, Lai JM, Chou TY, Chen CY, Su LJ, Lee YC, Cheng TS, Hong YR, Chou CK, Whang-Peng J, et al: VEGFA upregulates FLJ10540 and modulates migration and invasion of lung cancer via PI3K/AKT pathway. PLoS One 4: e5052, 2009.

5. Ogawa E, Takenaka K, Katakura H, Adachi M, Otake Y, Toda Y, Kotani H, Manabe T, Wada H and Tanaka F: Perimembrane Aurora-A expression is a significant prognostic factor in correlation with proliferative activity in non-small-cell lung cancer (NSCLC). Ann Surg Oncol 15: 547-554, 2008.

6. Rachet B, Woods LM, Mitry E, Riga M, Cooper N, Quinn MJ, Steward J, Brenner H, Estève J, Sullivan R and Coleman MP: Cancer survival in England and Wales at the end of the 20th century. Br J Cancer 99 (Suppl 1): S2-S10, 2008. 
7. Stewart DJ: Tumor and host factors that may limit efficacy of chemotherapy in non-small cell and small cell lung cancer. Crit Rev Oncol Hematol 75: 173-234, 2010.

8. Chen W, Zheng R, Baade PD, Zhang S, Zeng H, Bray F, Jemal A, Yu XQ and He J: Cancer statistics in China, 2015. CA Cancer J Clin 66: 115-132, 2016.

9. Mercer TR, Dinger ME and Mattick JS: Long non-coding RNAs: Insights into functions. Nat Rev Genet 10: 155-159, 2009.

10. Ren K, Xu R, Huang J, Zhao J and Shi W: Knockdown of long non-coding RNA KCNQ1OT1 depressed chemoresistance to paclitaxel in lung adenocarcinoma. Cancer Chemother Pharmacol 80: 243-250, 2017.

11. Carrizosa DR and Gold KA: New strategies in immunotherapy for non-small cell lung cancer. Transl Lung Cancer Res 4: 553-559, 2015

12. Lian Y, Cai Z, Gong H, Xue S, Wu D and Wang K: HOTTIP: A critical oncogenic long non-coding RNA in human cancers. Mol Biosyst 12: 3247-3253, 2016.

13. Ma C, Shi X, Zhu Q, Li Q, Liu Y, Yao Y and Song Y: The growth arrest-specific transcript 5 (GAS5): A pivotal tumor suppressor long noncoding RNA in human cancers. Tumour Biol 37: $1437-1444,2016$

14. Wu L, Jin L, Zhang $\mathrm{W}$ and Zhang L: Roles of long non-coding RNA CCAT2 in cervical cancer cell growth and apoptosis. Med Sci Monit 22: 875-879, 2016.

15. Pawar K, Hanisch C, Palma Vera SE, Einspanier R and Sharbati S: Down regulated lncRNA MEG3 eliminates mycobacteria in macrophages via autophagy. Sci Rep 6: 19416, 2016.

16. Shang C, Guo Y, Hong Y and Xue YX: Long non-coding RNA TUSC7, a target of miR-23b, plays tumor-suppressing roles in human gliomas. Front Cell Neurosci 10: 235, 2016.

17. Wu Q, Han L, Yan W, Ji X, Han R, Yang J, Yuan J and Ni C: miR-489 inhibits silica-induced pulmonary fibrosis by targeting MyD88 and Smad3 and is negatively regulated by lncRNA CHRF. Sci Rep 6: 30921, 2016.

18. Livak KJ and Schmittgen TD: Analysis of relative gene expression data using real-time quantitative PCR and the 2(-Delta Delta C(T)) method. Methods 25: 402-408, 2001

19. Jin J, Sun Z, Yang F, Tang L, Chen W and Guan X: miR-19b-3p inhibits breast cancer cell proliferation and reverses saracatinib-resistance by regulating PI3K/Akt pathway. Arch Biochem Biophys 645: 54-60, 2018.

20. Shang C, Guo Y, Zhang J and Huang B: Silence of long noncoding RNA UCA1 inhibits malignant proliferation and chemotherapy resistance to adriamycin in gastric cancer. Cancer Chemother Pharmacol 77: 1061-1067, 2016.
21. Liu G, Xiang T, Wu QF and Wang WX: Long noncoding RNA H19-derived miR-675 enhances proliferation and invasion via RUNX1 in gastric cancer cells. Oncol Res 23: 99-107, 2016.

22. Yan J, Dang Y, Liu S, Zhang Y and Zhang G: LncRNA HOTAIR promotes cisplatin resistance in gastric cancer by targeting miR-126 to activate the PI3K/AKT/MRP1 genes. Tumour Biol: Nov 30, 2016 (Epub ahead of print).

23. Tao Y, Han T, Zhang T, Ma C and Sun C: LncRNA CHRF-induced miR-489 loss promotes metastasis of colorectal cancer via TWIST1/EMT signaling pathway. Oncotarget 8: 36410-36422, 2017.

24. Wang K, Liu F, Zhou LY, Long B, Yuan SM, Wang Y, Liu CY, Sun T, Zhang XJ and Li PF: The long noncoding RNA CHRF regulates cardiac hypertrophy by targeting miR-489. Circ Res 114: 1377-1388, 2014

25. Tytgat GA, Voûte PA, Takeuchi S, Miyoshi I and Rutgers M: Meta-iodobenzylguanidine uptake in platelets, megakaryoblastic leukaemia cell lines MKPL-1 and CHRF-28-11 and erythroleukaemic cell line HEL. Eur J Cancer 31A: 603-606, 1995.

26. Schick BP, Petrushina I, Brodbeck KC and Castronuevo P: Promoter regulatory elements and DNase I-hypersensitive sites involved in serglycin proteoglycan gene expression in human erythroleukemia, CHRF 288-11, and HL-60 cells. J Biol Chem 276: 24726-24735, 2001.

27. Scholl S, Kirsch C, Böhmer FD and Klinger R: Signal transduction of c-Kit receptor tyrosine kinase in CHRF myeloid leukemia cells. J Cancer Res Clin Oncol 130: 711-718, 2004.

28. Chen L, Yan KP, Liu XC, Wang W, Li C, Li M and Qiu CG: Valsartan regulates TGF- $\beta /$ Smads and TGF- $\beta / \mathrm{p} 38$ pathways through lncRNA CHRF to improve doxorubicin-induced heart failure. Arch Pharm Res 41: 101-109, 2018.

29. Hennessy BT, Smith DL, Ram PT, Lu Y and Mills GB: Exploiting the PI3K/AKT pathway for cancer drug discovery. Nat Rev Drug Discov 4: 988-1004, 2005.

30. Xu S, Sui S, Zhang J, Bai N, Shi Q, Zhang G, Gao S, You Z, Zhan C, Liu F and Pang D: Downregulation of long noncoding RNA MALAT1 induces epithelial-to-mesenchymal transition via the PI3K-AKT pathway in breast cancer. Int J Clin Exp Pathol 8: 4881-4891, 2015.

31. Yang $\mathrm{C}, \mathrm{Li} \mathrm{X}$, Wang $\mathrm{Y}$, Zhao $\mathrm{L}$ and Chen W: Long non-coding RNA UCA1 regulated cell cycle distribution via CREB through PI3-K dependent pathway in bladder carcinoma cells. Gene 496: 8-16, 2012 .

(i) This work is licensed under a Creative Commons Attribution-NonCommercial-NoDerivatives 4.0 International (CC BY-NC-ND 4.0) License. 